\title{
Molecular Docking of Robustaflavone Derivatives on Pi3k Protein Target and The Correlation With Its Cytotoxic Activity on Cancer Cells
}

\author{
Sri Handayani* and Zalinar Udin \\ Research Center for Chemistry, Indonesian Institute of Sciences
}

\begin{abstract}
Robustaflavone derivatives have cytotoxic effect on cancer cell. Inhibition of PI3K on cancer cell has correlation with apoptotic induction. The aim of this research is to observe interaction from robustaflavone derivatives on PI3K receptor that may give contribution to the cytotoxic effect of the compounds on cancer cell line. Geometric optimization of robustaflavone derivatives structured was done used Hyperchem 7.5 software. Arguslab 4.0 I software with GAdock method applied for the docking step. The docking result showed that robustaflavone 7,4',7"trimethyl ether (RTE) has affinity on PI3K target receptor which gave the lowest Gibbs free energy $(\Delta \mathrm{G}-10,855 \mathrm{kcal} / \mathrm{mol})$.
\end{abstract}

Keywords: robustaflavone, PI3K, cancer, docking

\section{INTRODUCTION}

Phosphatidylinositol-3-kinase (PI3K) has been known as an important growth and survival pathway of the cell, and pathway activation is frequently found in human cancers (1). A key downstream effector of $\mathrm{PI} 3 \mathrm{~K}$ is the serinethreonine kinase Akt which in response to PI3Kactivation, phosphorylates and regulates the activity of a number of targets including kinases, transcription factors and other regulatory molecules. Akt is one kinase responsible to inactivate $\mathrm{Bad}$, one of proapoptotic protein, through phosphorylation. Akt activation has also been shown to activate NF- $\mathrm{KB}$-mediated transcription. Activation of NF- $\kappa B$ can suppress apoptosis through induction of antiapoptotic proteins (2). The PI3K pathway plays a critical role in regulating apoptosis, which is induced by many chemotherapeutic agents (3).

Many studies report that plant-compounds are potential for oncogene-negative regulator and tumor suppressor gene-positive regulator, which mean that those are potential as anticancer (4). Selaginella doederleinii Hieron (SD) is one of Indonesian plant (5) that has antiproliferative effect on cancer cell and antiviral activity $(6,7,8,9)$. The SD-compounds that have been known are biflavonoid $\quad(2,2 ", 3,3$ "-tetrahydrorobustaflavone $7,4^{\prime}, 7^{\prime \prime}$-trimethyl ether, robustaflavone 7,4',7"trimethyl ether, robustaflavone 4'-methyl ether, amentoflavone derivatives), alkaloid, and lignan $(8,10,11)$. The SD-robustaflavone derivatives are biapigenin which have cytotoxic effect on cancer cells (8). Apigenin is a flavonoid that decreased cell survival and apoptosis through dephosphorylation of Akt resulted in inhibition of its kinase activity, which was followed by reduced phosphorylation of proapoptotic proteins $\mathrm{BAD}$ (12).

Fisetin is a tetrahydroxyflavone that induce apoptosis through inhibition of phosphatidylinositol 3-kinase and phosphorylation of Akt at $\mathrm{Ser}^{473}$ and $\mathrm{Thr}^{308}$ (13). The aim of this research is to observe affinity and interaction from robustaflavone derivatives on $\mathrm{PI} 3 \mathrm{~K}$ receptor that may give contribution to the cytotoxic effect on cancer cell line.

\section{MATERIALS AND METHODS}

\section{Docking}

In the present work, all the ligands used were performed with HyperChem 7.0 for Windows Molecular Modeling System. Before the docking calculation of the ligands, the structures were fully optimized. Argus Lab 4.0 with GAdock method and rigid ligand was used to perform all the docking techniques.

*Corresponding author e-mail : anix_fa_83@yahoo.com 
The crystal structure of PI3K used for the present study was found as complex with inhibitor staurosprorine (crystal structure was downloaded from Protein Data Bank (1E8Z) as PDB files).
The whole procedure of docking was repeated in three replications. Concluding docking results were parameterized in terms of docking score (Gibbs free energy/ $\Delta \mathrm{G}$ ) in $\mathrm{kcal} / \mathrm{mol}$.

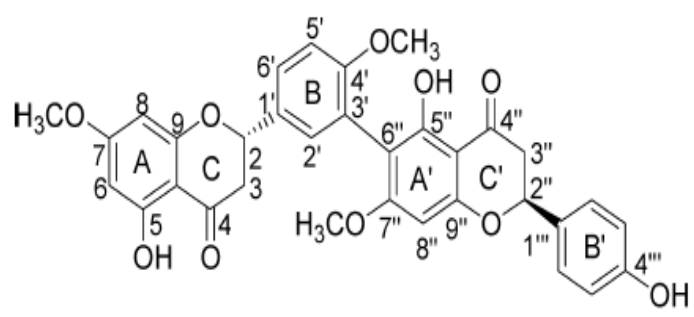<smiles>[R]c1cc(O)c2c(=O)cc(-c3ccc(OC)c(-c4c([R2])cc5oc(-c6ccc(O)cc6)cc(=O)c5c4O)c3)oc2c1</smiles>

$$
\begin{aligned}
2 \mathrm{R}_{1} & =\mathrm{OCH}_{3}, \mathrm{R}_{2}=\mathrm{OCH}_{3} \\
3 \mathrm{R}_{1} & =\mathrm{OH}, \mathrm{R}_{2}=\mathrm{OH}
\end{aligned}
$$

Figure I. Structure of $S$. doederleinii biflavonoid compounds (8). (I) 2,2',3,3'-tetrahydrorobustaflavone 7,4',7'-trimethyl ether (ThRTE); (2) Robustaflavone 7,4',7'-trimethyl ether (RTE); (3) robustaflavone 4'-methyl ether (RME).

\section{RESULTS AND DISCUSSION}

\section{Docking of robustaflavone derivatives- PI3K reseptor}

This study presented ligand-receptor interaction assay by ArgusLab docking. On the first study, PI3K-Quercetin (pdb code: 1E8W) would be choosen as a model because quercetin and robustaflavone are flavonoid. Nevertheles, this model is invalid to be used because the method validation showed that the RMSD value $>2$ with both of ArgusDock and GADock methods. Then, the chosen one is PI3KStaurosporin (pdb code: 1E8Z) which the RMSD value on the method validation $<2$. The staurosporin binding site on PI3K receptor (Fig. 4B) is similar with quercetin binding site on $\mathrm{PI} 3 \mathrm{~K}$ receptor. Staurosporin is an alkaloid that induces apoptosis through inhibition of protein kinase. The result of method validation on protein with pdb code $1 \mathrm{E} 8 \mathrm{Z}$ showed that the lowest Gibbs energy $(\Delta \mathrm{G})$ is AGDock-rigid, followed by GADock-flexible, GADock-rigid, and AGDock-flexible with $\Delta \mathrm{G}$ values are 12,020 ; $-11,909 ;-11,644$; and $-11,426 \mathrm{kcal} / \mathrm{mol}$ respectively. All of the methods are valid because RMSD value from the four methods are less than 2 (RMSD <2). 
Three compounds from robustaflavone derivatives (Fig. 3) that to be used as ligands, ie 2,2',3,3'-tetrahydrorobustaflavone 7,4',7'trimethyl ether (ThRTE), robustaflavone 7,4',7'trimethyl ether (RTE), and robustaflavone 4'methyl ether (RME) have been optimized

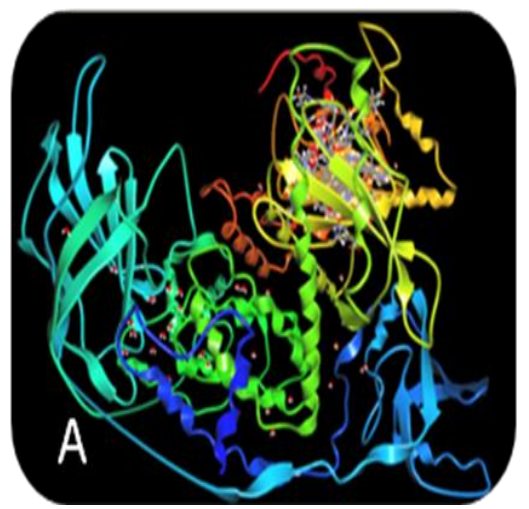

$10.628 \mathrm{kcal} / \mathrm{mol}$ and $-9.686 \mathrm{kcal} / \mathrm{mol}$ respectively (Table I). The RTE and ThRTE docking scores are almost similar and have lower energy than RME. It was the same results with $\mathrm{IC}_{50}$ values (Table I), which RTE has the lowest $\mathrm{IC}_{50}$, followed by ThRTE, and RME.

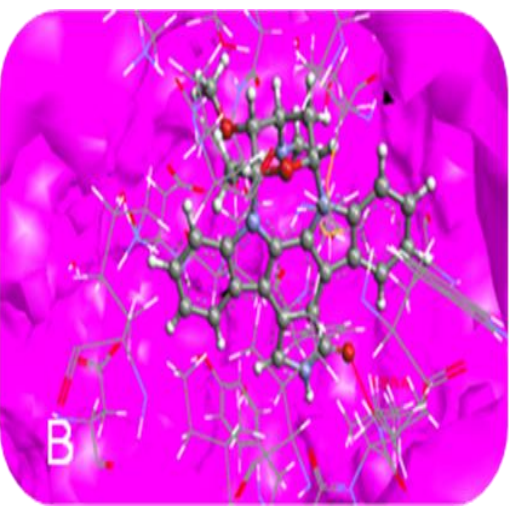

Figure 2. Experimental ligand and its bounded to PI3K reseptor (19) was downloaded from www.rcsb.org/pdb/ (pdb: IE8Z). A. PI3K (3D) protein reseptor; B. interaction of staurosporin (experimental ligand) on PI3K receptor.

The previously with Hyperchem geometry optimization. The robustaflavone derivatives were interacted on the $\mathrm{PI} 3 \mathrm{~K}$ receptor at staurosporin-binding site (Fig. 4). The first chosen method that to be used is AGDock-rigid, followed by GADock-flexible, GADock-rigid, amount of hydrogen bond (H-bond) from the ligand-PI3K interaction (Table 1) was not affected to $\Delta \mathrm{G}$ score. Its mean that $\Delta \mathrm{G}$ score from ligand-PI3K interaction was not only depend on H-bond. Nevertheles, the bonding of ligand on the specific amino acid on PI3K
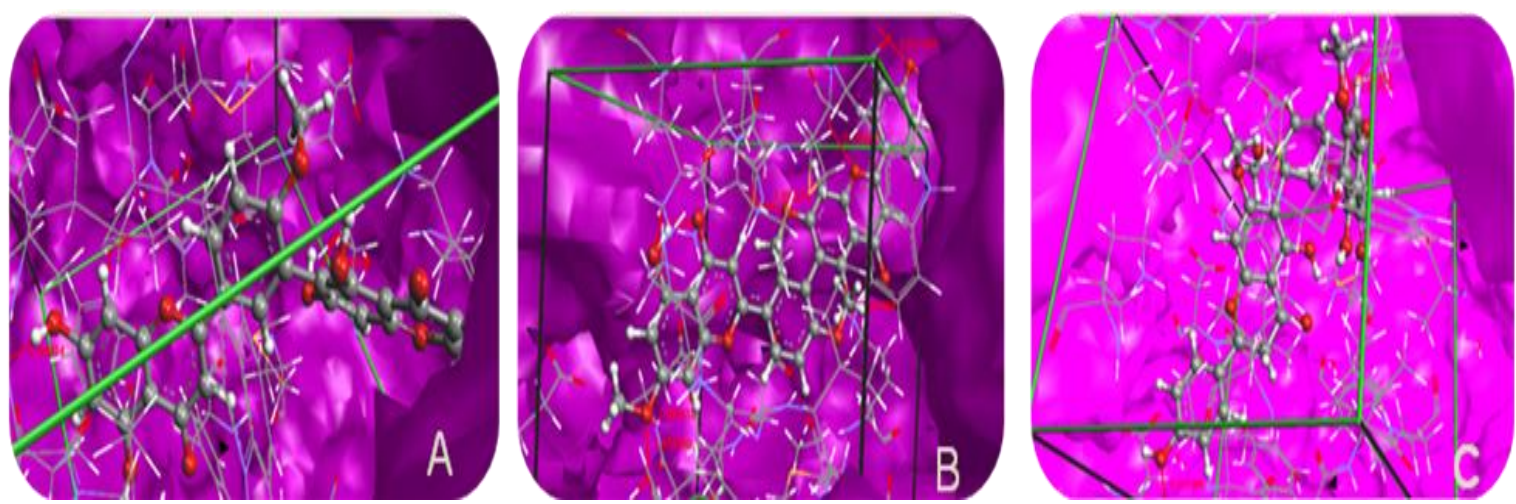

Figure 3. Interaction of robustaflavone derivatives on PI3K receptor. A. PI3K-RME; B. PI3K-RTE; C. PI3K-ThRTE.

and AGDock-flexible. Because of failure on the docking result when docking of PI3K-ligands was done with AGDock-rigid and GADock flexible, the next docking of PI3K-ligands was done with GADock-rigid.

The results showed that RTE has the lowest energy and followed by ThRTE and RME with docking score $(\Delta \mathrm{G})$ are $-10.855 \mathrm{kcal} / \mathrm{mol}$, - receptor through hydrogen bond was affected to $\Delta \mathrm{G}$ score. The lowest energy of RTE is affected by its bonding on Lys ${ }^{833}$ on ATP-binding site of $\mathrm{PI} 3 \mathrm{~K}$ receptor. Mechanism of PI3K inhibition by LY294002, a PI3K inhibitor, was also shown to involve covalent attack of $\mathrm{Lys}^{833}$ and Val ${ }^{822}$ within the ATP-binding site of PI3K at an electrophilic site on the compound (14). Similar 
with Knight and Shokat description (14), the mechanism of RTE-PI3K interaction was that the oxygen atom of RTE binds to Lys ${ }^{833}$ through hydrogen bond and makes extensive hydrophobic interactions with residues that form the top and bottom of the ATP-binding pocket. According to the results, RTE can be candidate for PI3K inhibitor.

Recent studies indicate that numerous components of the PI3K/AKT pathway are targeted by amplification, mutation and translocation more frequently than any other pathway in cancer patients, with resultant activation of the pathway. This warrants exploiting the PI3K/AKT pathway for cancer drug discovery (15). Quercetin, luteolin, and ursolic acid are potent inhibitors of proliferation and inducers of apoptosis on many cancer cells through PI3K pathway $(16,17)$. Isoginkgetin, a biflavonoid from Metasequoia glyptostroboides, inhibited HT1080 tumor cell invasion. Isoginkgetin regulated MMP-9 production via $\mathrm{PI} 3 \mathrm{~K} / \mathrm{Akt} / \mathrm{NF}-\mathrm{KB}$ pathway, as evidenced by the findings that isoginkgetin inhibited activities of both Akt and NF-KB (18). The cytotoxic activities of robustaflavone derivatives, biflavonoid compound in Selaginella doederleinii Hieron, possibly mediated by PI3K inhibition. The cytotoxic effect of robustaflavone derivatives on cancer cells promise the future research about cell cycle inhibition or apoptosis mechanism mediated the cytotoxic effect.

Table I. Docking result and $I C_{50}$ value of robustaflavone derivatives

\begin{tabular}{|c|c|c|c|c|c|c|c|}
\hline \multirow[b]{2}{*}{ No } & \multirow[b]{2}{*}{ Ligand } & \multirow{2}{*}{$\begin{array}{c}\text { Docking } \\
\text { score } \\
(\Delta \mathbf{G}) \\
\text { kcal/mol }\end{array}$} & \multirow{2}{*}{$\begin{array}{c}\mathrm{H}- \\
\text { bonds }\end{array}$} & \multirow{2}{*}{$\begin{array}{c}\text { Hydrogen bond lengths and } \\
\text { residues }\end{array}$} & \multicolumn{3}{|c|}{$\left.I^{\prime} C_{50}(\mu M)^{*}\right)$} \\
\hline & & & & & $\begin{array}{l}\mathrm{HCT} \\
116\end{array}$ & $\begin{array}{l}\mathrm{NCl}- \\
\mathrm{H} 358\end{array}$ & K562 \\
\hline
\end{tabular}

Staurosporin

(experimental ligand)

I.

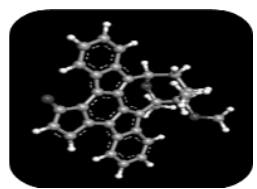
with atom $\mathrm{O}$ ketone on the ligand : $2.707 \AA$
$, 2^{\prime}, 3,3^{\prime}-$

tetrahydrorobustafla

vone $7,4^{\prime}, 7^{\prime}$ -

trimethyl ether

(ThRTE)

2.

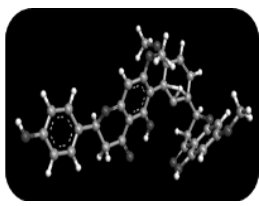

$-10.628$

3
Atom $\mathrm{N}$ in residue 890 Lys with $\mathrm{O}$ number 13874 on the ligand: $2.9 \AA$ Á

Atom $\mathrm{N}$ in residue 802 Lys with $O$ number 13877 on the ligand: $2.66 \AA$.

Atom $S$ in residue 869 Cys with O number 13903 on the ligand: $2.25 \AA ̊$
23.5 28.8

Atom $\mathrm{N}$ in residue 964 Asp with $O$ number 13877 on the ligand: $2.95 \AA$ Á

Atom $\mathrm{O}$ in residue $867 \mathrm{Tyr}$ with $O$ number 13877 on the ligand: $1.92 \AA ̊$

Atom $\mathrm{N}$ in residue $\mathbf{8 3 3}$ Lys with $O$ number 13876 on the ligand: $25 \AA$

Atom $\mathrm{N}$ in residue $805 \mathrm{Ala}$ with $O$ number 13894 on the ligand: $2.7 \AA$ Á

Atom $O$ in residue 758 Asp with $O$ number 13905 on the ligand: $2.56 \AA$ ̊́

Atom $O$ in residue $806 \mathrm{Ser}$ with $O$ number 13902 on the 


\begin{tabular}{|c|c|c|c|c|c|c|c|}
\hline & & & & $\begin{array}{l}\text { ligand: } 2.77 \AA \\
\text { Atom } N \text { in residue } 890 \text { Lys } \\
\text { with } O \text { number } 13903 \text { on the } \\
\text { ligand: } 2.89 \AA\end{array}$ & & & \\
\hline 4. & $\begin{array}{l}\text { Robustaflavone 4'- } \\
\text { methyl ether (RME) }\end{array}$ & -9.686 & 3 & 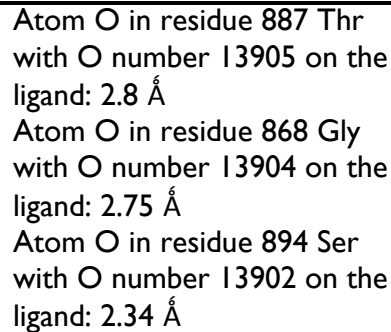 & $>100$ & $>100$ & $>100$ \\
\hline
\end{tabular}

*) Lee et al., 2008 (8)

\section{CONCLUSION}

The cytotoxic activity of robustaflavone derivatives on cancer cell line can be related to the affinity and interaction of the compounds on PI3K receptor.

\section{ACKNOWLEDGEMENT}

This work was supported by The Project of Kompetitif LIPI 2010 and all of the members of the project.

\section{REFERENCES}

Brachmann, S.M., Hofmann, I., Schnell, C., Fritsch, C., Wee, S., Lane, H., Wang, S., Garcia-Echeverria, C. and Maira, S., 2009, Specific apoptosis induction by the dual $\mathrm{PI} 3 \mathrm{~K} / \mathrm{mT}$ Tor inhibitor NVPBEZ235 in HER2 amplified and PIK3CA mutant breast cancer cells, PNAS, 106(52), 22299-22304.

Thompson, J.E. and Thompson, C.B., 2004, Putting the Rap on Akt, J. Clin. Oncol., 22(20), 42 I7-4226.

Lu, Y., Wang, H. and Mills, G.B., 2003, Targeting PI3K-Akt Pathway For Cancer Therapy, Rev Clin Exp Hematol, 7(2), 205-228.

Cardenas, M.E., Sanfridson, A., Cutler, N.S. and Heitman, J., 1998, Signal Transduction Cascade as Targets for Therapeutic Intervention by Natural Products, TIBTECH, 16, 427-433.

Dalimartha, S., 1999, Atlas Tumbuhan Obat Indonesia, Jilid I, Trubus Agriwidya, Jakarta, 29-3I.

Silva, G.L., Chai, H., Gupta, M.P., Farnsworth, N.R., Cordell, G.A., Pezzuto, J.M., Beecher, C.W.W. and Kinghorn, A.D.,
1995, Cytotoxic biflavonoids from Selaginella willdenowii, Phytochemistry, 40(I), 129-134.

Ma, S., But, P.P., Ooi, V.E., He., Y., Lee, S.H., Lee, S. and Lin, R., 200I, Antiviral Amentoflavone from Selaginella sinensis, Biol. Pharm. Bull., 24(3), 3|I-3|2.

Lee, N.Y., Min, H.Y., Lee, J., Nam, J.W., Lee, Y.J., Han, A.R., Wiryawan, A., Suprapto, W., Lee, S.K. and Seo, E.K., 2008, Identification of a New Cytotoxic Biflavanone from Selaginella doederleinii, Chem. Pharm. Bull., 56(9), I360-136I.

Tan, W.J., Xu, J.C., Li, L., and Chen, K.L., 2009, Bioactive compounds of inhibiting xanthine oxidase from Selaginella labordei, Nat Prod Res., 23(4), 393-398.

Lin, R.C., Seguin, E., Tillequin, F. and Koch, M., 1987, New Alkaloid Glycosides from Selaginella doederleinii, J. Nat. Prod., 1987, 50(3), 422-426.

Lin, R.C., Skaltsounis, A.L., Seguin, E., Tillequin, F. and Koch, M., 1994, Phenolic Constituents of Selaginella doederleinii, Planta medica, 60(2), I68-170.

Kaur, P., Shukla, S. and Gupta, S., 2008, Plant flavonoid apigenin inactivates Akt to trigger apoptosis in human prostate cancer: an in vitro and in vivo study, Carcinogenesis, 29(II), 2210-2217.

Khan, T.H. and Sultana, S. 2006, Apigenin induces apoptosis in Hep G2 cells: possible role of TNF-alpha and IFNgamma, Toxicology, 2 I 7(2-3), 206-I2.

Knight, Z.A. and Shokat, K.M., 2007, Chemically targeting the PI3K family, Biochemical Society Transactions, 35(2), 245-249.

Hennessy, B.T., Smith, D.L., Ram, P.T., Lu, Y. and Mills, G.B., 2005, Exploiting the PI3K/AKT Pathway for Cancer Drug 
Discovery, Review, Nature Reviews Drug Discovery, 4(I 2), 988- 1004.

Gulati, N., Laudet, B., Zohrabian, V.M., Murali, R. and Jhanwar-Uniyal, M., 2006, The antiproliferative effect of Quercetin in cancer cells is mediated via inhibition of the PI3K-Akt/PKB pathway, Anticancer Res., 26(2A), I I77-I I8I.

Xavier, C.P.R., Lima, C.F., Preto, A., Seruca, R., Ferreira,M.F. and Wilson, C.P., 2009, Luteolin, quercetin and ursolic acid are potent inhibitors of proliferation and inducers of apoptosis in both KRAS and BRAF mutated human colorectal cancer cells, Cancer Letters, 28 I (2): I 62-I70.

Yoon, S., Shin, S., Lee, H., Chun, H. and Chung, A., 2006, Isoginkgetin inhibits tumor cell invasion by regulating phosphatidylinositol 3-kinase/Aktdependent matrix metalloproteinase-9 expression, Mol Cancer Ther, 5(II), 2666-2675. 